\title{
Encontros e desencontros da Psicologia com a Teologia no estudo da Religião ${ }^{1}$
}

\author{
Encounters and Disencounters between \\ Psychology and Theology in Regard to the Study of Religion
}

Sidnei Vilmar Noé2

RESUMO

Este artigo retoma a discussão da relação conflituosa entre psicologia e teologia no que tange à compreensão de ciência no estudo da religião. Por um lado, autores como M. Utsch assinalam um crescente embaçamento dos contornos dessas áreas em função do também ascendente influxo da literatura de autoajuda na pesquisa acadêmica. Esta se dá, muitas vezes, mais por uma apropriação inadequada da terminologia e da metodologia alheia do que através de uma discussão crítica das bases conceituais recíprocas. Desta, por outro lado, poder-se-ia esperar um enriquecimento recíproco, no qual especialmente a Psicologia seria remetida à discussão de seus fundamentos teológico-filosóficos, enquanto a Teologia seria questionada a respeito de sua compreensão antropológica no que concerne à existência real e concreta da vida das pessoas sob o aspecto psicológico.

Palavras-chave: Psicologia da Religião. Psicologia. Teologia.

\section{ABSTRACT}

This article takes up the discussion of the conflicting relationship between psychology and theology regarding the understanding of science in the study of religion. First, as authors like $\mathrm{M}$. Utsch indicate, there is an increased blurring of the outlines of these areas due to the ascending influence of the self-help writings in academic research literature. This occurs most often by improper use of the terminology and methodology of each other than through a critical discussion of the mutual conceptual basis. This, on the other hand, may be expected through a reciprocal enrichment, where especially psychology would be referred to the discussion of their theological and philosophical basis, while theology should be questioned about his anthropological understanding regarding the actual existence and concrete life of the human being under psychological aspect.

Keywords: Psychology of Religion. Psychology. Theology.

\footnotetext{
' Recebido em 01/10/2015. Aprovado em 01/02/2016.

${ }^{2}$ Professor Doutor do Programa de Pós-Graduação em Ciência da Religião da UFJF. E-mail: sidnei.noe@ufjf.edu.br.
} 


\section{Introdução}

Clássica é a tese de que não há ainda a Psicologia da Religião. Existe uma variedade de autores consagrados, de temas abordados e de pesquisas realizadas ao longo de quase um século, que, grosso modo, poderiam ser situados em uma área denominada de Psicologia da Religião.

(...) a Psicologia da Religião não existe. Em distinção a uma Psicologia da Religião rigorosamente empírica, quantificadora (Grom, 1992; Moosbrugger; Zwingmann; Frank, 1996), uma compreendida teologicamente (Fraas, 1990), uma aninhada na Ciência da Religião (Zinser, 1988;Stolz, 1988), uma orientada fenomenologicamente (Wyss, 1991; Wit, 1993), uma derivada das Ciências da Cultura (Popp-Baier, 1990; Belzen, 1997) ou outra fundamentada na Psicanálise (Henseler, 1995), aqui se efetuará uma contribuição epistemologicamente fundamental para a compreensão dos aspectos psicológicos da Religião, da Religiosidade e da Espiritualidade. ${ }^{3}$

Aplicando certos filtros, esses diferentes enfoques metodológicos também poderiam ser perfeitamente situados em outras disciplinas, como a Filosofia, a Ciência da Religião, a Teologia e, inclusive, a própria Psicologia. Surge, pois, a pergunta elementar pelo próprio estatuto epistemológico da Psicologia da Religião. E esta somente poderá ser respondida a contento se, antes, for definida a própria Psicologia que serve de base para a definição da Psicologia da Religião. É necessário, desse modo, trilhar o seguinte caminho: a partir da discussão do próprio estatuto epistemológico da Psicologia, chegar a uma compreensão de Psicologia da Religião, que, por sua vez, ofereça uma base para a interlocução com a Teologia e a Ciência da Religião.

\section{De quê Psicologia estamos falando?}

A Psicologia, enquanto área acadêmica específica, assim como a Psicologia da Religião, também carece de um estatuto epistemológico definido que assegure a sua unidade teórica e metodológica. Emersa das profundezas da Filosofia e da Teologia, na virada para o século $\mathrm{XX}$, sente a necessidade de definir-se como ciência objetiva, o que equivale a dizer, como ciência natural e empírica, para pleitear seu reconhecimento acadêmico.

A jovem e ascendente psicologia inicialmente estava ocupada em desvencilhar-se de suas raízes teológicas e filosóficas. Por isso, no início, ela prescreveu para si

\footnotetext{
${ }^{3}$ Michael UTSCH, Religionspsychologie, p. 13.
} 
totalmente o ideal epistemológico das ciências naturais de medição e cálculo, para perfilar-se enquanto ciência social empírica. ${ }^{4}$

E, pode-se afirmar que, até hoje, não obstante a diversidade de escolas que compõem a ciência psicológica, prevaleceu como linha mestra essa orientação fundamental no paradigma científico das ciências empírico-positivas. Isso tem por consequência que, também ao longo de sua história, um conteúdo fundamental de sua área de pesquisa tenha se perdido ou, ao menos, tenha-se grande dificuldade em estudá-lo: a religião e os seus cognatos, a religiosidade e a espiritualidade. Basicamente, porque "[e]xperiências religiosoespirituais, todavia, se retraem a uma explicação racional, porque um componente essencial desta experiência - Deus ou uma realidade supra-humana - não é acessível ao modelo científico de análise". ${ }^{5}$ Historicamente, entretanto, este conteúdo Ihe era constitutivo, pois, "[o]riginalmente atribuiu-se à psicologia uma posição privilegiada na definição do conceito de religião"

A religião foi apresentada como uma vivência emocional individual, seja enquanto "sentimento do infinito" ou de "dependência absoluta"; como "estado anímico suscitado pelo numinoso", arrebatamento através do Sagrado ou ainda como "encontro vivencial com a realidade sagrada".

Assim, conforme M.Utsch, tem-se a seguinte situação: "Na psicologia germanófona, a religião não é um tema". ${ }^{\mathrm{E}} \mathrm{E}$, quando é tema, por exemplo, no estudo das experiências religiosas, estas são tratadas como um "fenômeno extravagante": "[p]elo visto, relacionam-se a essas inicialmente manifestações espetaculares como percepções extrassensoriais, experiências paranormais ou estados de consciência transpessoais; raramente, porém, uma vivência psíquica comum". ' Já nos EUA, haveria uma forma bem menos pré-condicionada e mais pragmática de lidar com a vivência e o comportamento religioso, o que, todavia, não implicaria uma distinta compreensão epistemológica e metodológica do paradigma da Psicologia.

Por fim, poderíamos perguntar pela relação entre Psicologia e Religião no contexto brasileiro. Esta é uma pergunta cujas respostas ainda precisam ser exploradas mais atentamente. Provisoriamente, é possível dizer que, por um lado, a herança do positivismo científico também deixou suas marcas aqui e, portanto, excluiu conceitualmente o estudo da religião da Psicologia acadêmica. Por outro, poder-se-ia dizer que, quando a religião é tema de estudos da Psicologia, estes seguem tendencialmente um viés empírico de pesquisa

\footnotetext{
${ }^{4}$ Idem, p. 369.

${ }^{5}$ Idem, p. 366.

${ }^{6}$ Idem, p. 368.

${ }^{7}$ Michael UTSCH, Religião e Psicologia, p. 368.

${ }^{8}$ Idem, p. 366.

${ }^{9}$ Idem, p. 367.
} 
psicológica aplicada ao estudo da religião. Não obstante, tem-se, gradativamente, aberto frentes de diálogo que, por um lado, buscam sobrepujar pré-conceitos recíprocos e, por outro, seguem um viés menos voltado a uma mera instrumentalização de conceitos psicológicos aplicados ao estudo da religião. E isso somente é possível à medida que a Psicologia se recorda de sua dupla-natureza: nascida das ciências do espírito e irmanada com as ciências da natureza. ${ }^{10}$

\section{Caminhos da Psicologia da Religião}

A Psicologia da Religião, ao longo de sua história secular, reflete os mesmos dilemas e desafios assinalados em relação à Psicologia, que Ihe serve de base:

A enorme diferença entre os modelos psicológicos para a explicação da religiosidade confunde. Desde modelos biológico-neurofisiológicos (...), passando por psicanalíticos Uones, 1991; Henseler, 1995) e interpretações terapêuticocomportamentais (Miller e Martin, 1988), a partir dos pressupostos do pensamento sistêmico (Stadlmeier, 1889; Etzold, 1992) ou da teoria genéticoestrutural (Oser e Reich, 1992), até mesmo modelos de consciência transpessoal (Zundel e Loomans, 1994) e explicações parapsicológicas (Mischo, 1991) são abarcados pelo seu amplo espectro. Acertadamente observa Stolz $[1988,175)$ que "a Psicologia da Religião... em si é completamente disparatada"."

Assim, conforme já indicava Karl Jaspers, porque a Psicologia como ciência não apresenta as condições necessárias para ser uma Totalwissenschaft ${ }^{2}$, pois prescinde dos pressupostos filosóficos e teológicos que Ihe apontam o zênite e o nadir, a Psicologia da Religião decorrente precisa buscar esta complementariedade necessária:

A Psicologia da Religião - compreendida como uma disciplina psicológica autônoma - depende de uma integração complementar das tradições empírica e hermenêutica, assim como de seus pontos de vista epistemológicos e cosmovisivos, porque estas buscam apreender e descrever psicologicamente a verdade objetiva e subjetiva da religião. Recentes concepções de pesquisa psicológica desenvolveram metodologias diferenciadas, que fazem jus, tanto a aspectos qualitativo-substanciais, quanto quantitativo-funcionais. ${ }^{13}$

${ }^{10}$ G. Paiva faz uma síntese do estado da arte no Brasil em: PAIVA, Geraldo José de et al . Psicologia da Religião no Brasil: a produção em periódicos e livros. Psic.: Teor. e Pesq., Braślia, v. 25, n. 3, Setembro de 2009. Disponível em: <http://www.scielo.br/scielo.php?script=sci_arttext\&pid=SO102377220090003000198 Ing=en\&2nrm=iso > Acesso em: 27 jun. 2013.

"Cf. Michael UTSCH, Religionspsychologie, p. 16.

12 "Nem a psicologia nem a sociologia dispõe de fundamento científico próprio. Quem se dedique a pesquisas em tal campo deve possuir treinamento científico especializado, seja em filologia, história, direito, fisiologia, medicina, teologia ouqualquer outro setor. Sem tal base, a pessoa se perderá em parolagem vazia." Cf. Karl JASPERS, Introdução ao pensamento filosófico, p. 66.

${ }^{13}$ Michael UTSCH, Religionspsychologie, p. 193. 
Subentende-se, que a concepção apresentada por Utsch pretende, do ponto de vista metodológico e epistemológico, abarcar justamente o objeto da fé transcendente, que em uma tradição puramente empírica estaria por princípio excluído. ${ }^{14} \mathrm{O}$ caminho de inclusão do transcendente passaria, a partir da complementação da tradição hermenêutica, pela integração da subjetividade no processo hermenêutico: não só a teoria, a metodologia e o objetivo da pesquisa deveriam ser comunicados explicitamente, mas também os comprometimentos metafísicos e axiológicos dos pesquisadores, pois esses influenciam a pesquisa e são relevantes na avaliação dos resultados. ${ }^{15}$

\section{Psicologia [da Religião] e Teologia: encontros e desencontros}

Não obstante a tese de $M$. Utsch de "que ignorância e suspeições recíprocas entre Psicologia e Teologia dificultaram um diálogo e, com isso, obstruíram o desenvolvimento da Psicologia da Religião na Alemanha"16, pode-se constatar que, ao longo da história, a Teologia mostrou-se aberta ao diálogo (conflituoso) com a Psicologia, se bem que o mesmo não valesse em sentido inverso. Especialmente, neste tocante, merece destaque a Psicologia Pastoral, no âmbito protestante e a Teologia Pastoral, no contexto católico. A partir de pioneiros, como o pastor $\bigcirc$. Pfister, desenvolveu-se um diálogo crítico significativo, por exemplo, quando da sua réplica a Freud em relação à obra o "Futuro de uma Ilusão", intitulada, a "Ilusão de um Futuro".

Conforme assinala $M$. Utsch, este diálogo se deu majoritariamente em relação à Psicologia do Profundo, com uma predileção especial do ramo protestante por S. Freud e da ala católica, por C. G. Jung. Seria isso também um indício de que no fundo são opções antropológicas que definem as preferências epistemológicas e metodológicas? Esta corrente, todavia, em muitos cursos de Psicologia sequer é considerada e manteve uma posição marginal. ${ }^{17}$ Apenas recentemente tem-se buscado um diálogo com a Gestalt, Terapias Sistêmicas, Terapias Breves, Comportamentais...

Do ponto de vista metodológico, contudo, a relação interdisciplinar ainda se ressente de uma reflexão mais pertinente, pois, muitas vezes, ela se estabelece nos moldes de uma ciência aplicada. Ou seja, utiliza-se outra ciência para preencher lacunas conceituais

\footnotetext{
${ }^{14}$ Segundo Théodore Flournoy, um dos princípios sobre os quais deve se fundamentar uma "autêntica psicologia da religião" é o da "exclusão de um Ser Superior". Cf. A. Ávila, Para Conhecer a Psicologia da Religião, p. 24.

${ }^{15}$ Desde Martin Heideger e Hans-Georg Gadamer, os pressupostos são inalienáveis na relação do ser com o mundo. A questão, todavia, está em explicitá-los ou sonegá-los; tematizá-los ou ignorá-los; torná-los conscientes ou mantê-los obscuros. Neste sentido também deve ser entendida a reivindicação de Théodore Flournoy de que "o psicólogo da religião estava obrigado a colocar entre parênteses sua posição pessoal em benefício de uma maior objetividade". Cf. A. Ávila, Para Conhecer a Psicologia da Religião, p. 17.

${ }^{16}$ Michael UTSCH, Tarefas e Limites da Psicologia da Religião, p. 546.

${ }^{17}$ Cf. Michael UTSCH, Religião e Psicologia, 368.
} 
e metodológicas da própria. $E$, do ponto de vista epistemológico, coloca-se a pergunta: em que medida as noções antropológicas distintas entre as várias escolas psicológicas e aquelas situadas na Teologia podem ser intercambiáveis?

\section{Religião e Psicologia como área da Ciência da Religião}

Uma vez que o conceito de Psicologia da Religião sugere a ideia da ciência psicológica aplicada ao estudo da religião, esta certamente deveria ter seu locus na própria Psicologia. Já uma compreensão de um diálogo crítico recíproco, deveria estabelecer uma nomenclatura diferente para a área: "Religião e Psicologia" poderia definir mais apropriadamente esta relação, na qual os diferentes aspectos religiosos tteológicofilosóficos) e psicológicos estariam incluídos de forma mais apropriada. Desenvolver essa noção, que já tem uma história, se bem que recente ${ }^{18}$, pode se tornar alvo de uma pesquisa de fôlego que repensa criticamente as relações entre Ciência da Religião e Teologia.

Tal empreendimento desprenderia a pesquisa acadêmica da religião de um duplo confinamento, sob a Psicologia, por um lado, e sob a Teologia, por outro. $\bigcirc$ primeiro jugo que se interpõe ao estudo desprendido da religião a partir da Psicologia se refere à sua submissão a uma autocompreensão natural e positiva de ciência que subjaz à maior parte da Psicologia acadêmica convencional e que, seguindo o critério proposto por Théodore Flournoy (1903, 1910), exclui metodologicamente o transcendente (metafísico). De acordo com a análise de Geraldo Paiva,

[n]ão [se] pode ignorar o coeficiente psicológico de transcendência no comportamento do crente que se sente "interpelado" pela realidade religiosa. $\bigcirc$ transcendente é excluído seja como objeto de estudo, seja como critério explicativo, mas o crente é portador de uma dupla convicção, tanto de sua existência real como de sua ação e eficácia no mundo e no homem. Prescindir desta convicção subjetiva do crente significaria fechar-se não só a uma correta leitura psicológica de sua religiosidade como também à compreensão da incidência que esta poderia ter na estruturação da personalidade (normal e patológica) e nos percursos de sua reestruturação. ${ }^{19}$

Um segundo jugo diz respeito à sujeição do estudo da religião ao cânone de determinada escola psicológica, respectivamente de sua autocompreensão da ciência psicológica, bem como de seus conceitos elementares e metodologias de pesquisa particulares. Se, por um lado, tal empreendimento significa um enriquecimento da pesquisa da religião sob os aspectos abarcados pelo enfoque privilegiado, por outro, reduz a

\footnotetext{
${ }^{18}$ Cf. A. ÁVILA, Para conhecer a Psicologia da religião, p. 11.

${ }^{19}$ G. J. PAIVA et al., A representação na religião, p. 42.
} 
religião aos conceitos que Ihe são fundamentais e que, inclusive, emanam do olhar sobre a religião inspirado pelos seus fundadores. ${ }^{20}$

Em terceiro lugar, a submissão a uma compreensão meramente funcional e descritiva, característica das abordagens empíricas, implica, geralmente, a perda do enfoque normativo e substantivo tão necessário à ciência que estuda a religião. Naturalmente, os elementos reunidos a partir de pesquisas funcional-descritivas logra ampliar o volume de dados sobre as religiões em sua manifestação histórico-contextual e que enriquecem os elementos disponíveis para a compreensão de determinada religião. Todavia, o elemento mais relevante para as ciências do espírito (humanas) é, justamente, a interpretação dos dados a partir de pressupostos teóricos previamente discutidos e definidos. No tocante à religião, em sentido estrito, sempre está em jogo a questão da verdade, uma vez que a própria religião, notadamente a cristã, autodefine-se como a verdade e a vida:

A psicologia da religião não reduz seu papel a uma mera descrição do fato religioso, mas deve fazer um juízo de valor sobre ele. (...)

O juízo normativo de verdade não diz respeito à "verdade" do fato religioso, mas às motivações que o originam e às consequências que comporta para a vida do sujeito, devendo avaliar entre a verdadeira e a falsa religiosidade. ${ }^{21}$

E, não por último, há o jugo das premissas subjacentes às respectivas teorias psicológicas e das escolas delas emergentes. Nesse tocante, é uma dupla submissão, pois as próprias teorias compreendem ideais cosmovisivos, nem sempre explicitados e discutidos, assim como os próprios autores possuem suas cosmovisões, muitas vezes, diluídas em sua abordagem da religião.

Não a Psicologia, mas concepções filosóficas e religiosas fornecem cosmovisões, que oferecem segurança ao indivíduo em uma totalidade imaginária. Concepções de tratamento psicoterápicas contêm muitas vezes um ideal antropológico irrefletido, o qual não é passível de ser fundamentado científico-empiricamente, mas somente cosmovisivo-filosoficamente. ${ }^{22}$

Por outro lado, também em relação à Teologia, compreendida como o estudo sistemático de determinada religião, particularmente do Cristianismo, sob o espectro de suas bifurcações confessionais, é necessário alcançar uma distância crítica. A primeira delas refere-se justamente ao necessário encapsulamento dogmático dessa área do saber, que, ao mesmo tempo, confina a religião sob seus ditames conceituais. A interlocução com a Psicologia permite um olhar menos aficionado sobre a própria crença e lhe revela os

\footnotetext{
${ }^{20}$ Para citar apenas um exemplo, cf. Ana-Maria RIZZUTO, Por que Freud rejeitou a Deus? São Paulo: Loyola, 2001.

${ }^{21}$ Cf. A. ÁVILA, Para conhecer a Psicologia da Religião, p. 18.

${ }^{22}$ Cf. M. UTSCH, Tarefas e limites da Psicologia da Religião, p. 548.
} 
traços humanos inexoravelmente nela incrustados. ${ }^{23}$ Com isso, serve-lhe de critério relativizador que distende possíveis distorções fundamentalistas e auxilia para um olhar autorreflexivo sobre a própria identidade e, consequentemente, fomenta atitudes mais abertas ao diálogo, mais tolerantes, mais flexíveis e que, ao mesmo tempo, não solapam as próprias bases teológico-filosóficas.

Soma-se a este aspecto o caráter "visionário", muitas vezes, associado à religião e que tende a perder o contato com a realidade. Não somente nos clássicos casos de visões proféticas, de enlevos místicos e de experiências extáticas, mas também de maneira ampla e generalizada na vida cotidiana do crente médio, onde este aspecto se faz presente. A religião suscita certo anelo de fuga do mundo e pode, inclusive, conduzir àquilo que $M$. Utsch denomina de Weltfremdheit, ou seja, uma condição de alienamento em relação ao mundo. Neste contexto, a crítica à religião de $\mathrm{S}$. Freud justamente chama a atenção para o princípio da realidade e, em sua contramão, para a ilusão nutrida pela religião e que pode implicar uma infantilização dos crentes.

Se, por um lado, a fundamental busca pela verdade torna a ciência sobre a religião propensa a assumir posições substantivas, essenciais, normativas, o que a reconcilia com a sua origem na Filosofia e na Teologia, por outro, muitas vezes, tende a relativizar a representação social, política, cultural e histórica a ela relacionada. Este déficit pode ser compensado por noções que acentuam o aspecto funcional da religião, entre elas, o aporte psicológico que, justamente, ocupa-se com a descrição funcional dos aspectos anímicos a ela relacionados: "Se da concepção substantiva assumimos sua referência ao sagrado, à divindade, ao último... a concepção funcional nos mantém alerta para não esquecer o aspecto de busca do importante, do absoluto, que se dá no homem religioso (...)."24

E, finalmente, estreitamente relacionado ao aspecto anterior, se o elemento distintivo do comportamento religioso humano é, justamente, a sua referência ao transcendente, o que legitima a existência de uma área da ciência particular para o seu estudo, este estudo precisa concentrar-se perspectivamente "no lado de cá", ou seja, no imanente. Pois o objeto propriamente dito deste estudo não é a divindade, o sagrado, o sobrenatural, em si, mas a relação do ser humano com este. Portanto, uma interlocução com as ciências do humano, particularmente, do comportamento humano, sob a tríade afetiva, cognitiva e conativa torna este foco possível. Assim compreendido, o objeto da Psicologia da Religião, "é o homem na qualidade de religioso: suas motivações, seus desejos, suas experiências, suas atitudes etc., expressos em seus comportamentos." ${ }^{25}$

\section{Religião e Psicologia se (des)encontram no estudo da alma humana}

\footnotetext{
${ }^{23}$ Vale lembrar dois clássicos no que concerne ao estudo da personalidade religiosa e sua repercussão na Teologia: E. ERIKSON, The Young Man Luther, 1958 e O. PFISTER, Die Frommigkeit des Grafen Ludwig von Zinzendorf, 1910.

${ }^{24}$ Cf. A. ÁVILA, Para conhecer a Psicologia da Religião, p. 14s.

${ }^{25}$ Cf. A. ÁVILA, Para conhecer a Psicologia da Religião, p. 15.
} 
A "maçã da discórdia" entre a Religião e a Psicologia é a alma humana:

O assunto é explosivo, porque a acentuada rivalidade entre a Psicologia e a Teologia tem dificultado um diálogo conjunto. $O$ objeto de disputa com o qual flertam tanto a Psicologia quanto a Teologia é a alma - sua essência, sua definição e sobre o melhor caminho para o seu desenvolvimento. ${ }^{26}$

Se, até a modernidade, o conhecimento da alma humana era assunto da religião e, consequentemente, do seu estudo sistemático-filosófico, histórico-contextual e teóricoprático, a Teologia, o advento das disciplinas autônomas que se dedicam ao estudo do ser humano, notoriamente da Psicologia, fez com que, no mínimo, o predomínio desse conhecimento se tornasse motivo de disputa. E, com a novidade deste estudo, ao pautarse no cânone do método científico, isto é, do método empírico-descritivo-funcional, os segredos, os mistérios, que antes povoavam este conhecimento, começaram a ser desmistificados por leis mecanicistas, a exemplo daquelas aplicadas ao conhecimento dos fenômenos da natureza em geral.

A Psicologia assumiu seu modelo ideal do Humanismo, isto é, do grande movimento de iluminação e libertação do século XVIII. Neste período consumouse uma mudança notável da magia à ciência. Para a medicina, isto teve por consequência, que ela abandonasse seus ingredientes místicos e ocultos tradicionais. $\bigcirc$ "médico academicamente formado expulsou o curandeiro; o cirurgião, o barbeiro; a aplicação de raios, o ferro incandescente e a conversação, o exorcismo". Autodefinição, transparência dos métodos e teorias, assim como o controle racional sobre a imprevisível vida da alma se tornaram os ideais a serem perseguidos, nos quais também a Psicoterapia se pautou. Esta compreensão é cunhada pela crença positivista na força vital da ciência natural e da técnica. Na sociedade moderna, portanto, a saúde ocupou o lugar da cura e o medicamento substitui a participação na Eucaristia. ${ }^{27}$

Concomitantemente, o conhecimento milenar sobre a alma, cuja matriz ignorava a estrita distinção entre o físico e o metafísico, foi gradativamente sendo substituído por um conhecimento que faz uma clivagem entre estas dimensões, prescrevendo-se categoricamente o ideal de voltar-se exclusivamente ao material, físico, orgânico e imanente. Mesmo o protesto do Romantismo, por exemplo, de Carl Gustav Carus, que destacou o papel primaz do inconsciente, mas também o de Sigmund Freud, que acentuou este mesmo aspecto ou, até mesmo, o de Carl Gustav Jung, que concebeu toda sua teoria sobre o papel fundamental do inconsciente, não lograram efeito nessa redução da compreensão da alma humana ao seu aspecto material e racionalista. $E$, mais recentemente, o avanço da importância da pesquisa em neurociência, inclusive, radicaliza esta tendência. É

\footnotetext{
${ }^{26}$ M. UTSCH, Ist Glaube nur psychologisch erklärbar?, p. 4.

${ }^{27}$ M. UTSCH, Ist Glaube nur psychologisch erklärbar?, p. 4.
} 
necessário, contudo, não ignorar essa "dupla natureza" da Psicologia: "A Psicologia tem uma dimensão que a aproxima das ciências naturais e biológicas e outra dimensão que a aproxima das ciências históricas e hermenêuticas". ${ }^{28}$

Conforme constata Michael Utsch, mais recentemente, nota-se um duplo desenvolvimento: por um lado, a Psicologia, em diversos desdobramentos psicoterápicos procura compensar este déficit da perda do conhecimento religioso da alma humana por uma "evidente espiritualização" e, por outro, a Teologia, por exemplo, na Pastoral (poimênica), assumindo a relevância do conhecimento sobre a alma humana, adquirido através da Psicologia, efetua uma "psicologização de seus conteúdos". ${ }^{29}$ Com isto, conforme o mesmo autor, questões fundamentais acerca da compreensão de ser humano foram negligenciadas. ${ }^{30}$

Por outro lado, é possível e necessária uma cooperação entre ambos os tipos de conhecimento para o estudo da alma humana:

\begin{abstract}
Porque a fé também possui um lado humano - a vivência individual da fala e da ação de Deus, assim como a constituição da relação pessoal com Deus - as reflexões psicológicas têm sua justificativa e fazem sentido. A Psicologia e a Teologia podem, assim, locupletar suas visões parciais. Ambas perseguem, por caminhos distintos, o objetivo de alcançar o ser humano integral - diante de Deus. A Psicologia traz, sobretudo, a importância dos sentimentos, da memória, da força representacional e da qualidade relacional, enquanto a fé, o conhecimento e a experiência sobre a realidade e a eficácia do Deus triúno. Para a Teologia, através de uma colaboração com a Psicologia, pode se tornar acessível novamente e de maneira mais profunda o seu potencial terapêutico, enquanto para a Psicologia, a sua forma de lidar com questões religiosas. ${ }^{31}$
\end{abstract}

Portanto, nem a pressuposição ou a assunção cega de elementos religiosos pela Psicologia, ou de modelos psicoterápicos pela Teologia, tampouco, a estrita distinção entre as competências de ambos os tipos de conhecimento é adequada. Naturalmente, é necessário que aquele[a] que se propõe a este diálogo crítico recíproco entre Teologia e Psicologia, entre religião e ciência psicológica, assinalando elementos de divergência e de confluência, busque um aprofundamento em ambas as áreas. Se, todavia, este aprofundamento requer que o psicólogo da religião seja praticante ou teólogo, que seja alguém preparado na clínica e teoria psicológica, é motivo de controvérsia. Certamente, há diferenças entre as abordagens de alguém "iniciado", ou seja, "de dentro" da religião ou da Psicologia, em relação a alguém que olha para ambos os campos "de fora", o que não implica que um seja mais ou menos válido que o outro.

\title{
6. Áreas de intersecção crítica, segundo M. Utsch
}

${ }^{28}$ G. J. de PAIVA, Ciência, Religião, Psicologia: Conhecimento e Comportamento, p. 566.

${ }^{29}$ Cf. M. UTSCH, Ist Glaube nur psychologisch erklärbar?, p. 6.

${ }^{30}$ Idem, p. 6.

${ }^{31}$ Idem, p. 12. 
A pesquisa psicológica norte-americana sobre a personalidade dedica-se recentemente à revisão do "modelo de cinco fatores", denominado de "os cinco grandes" (the big five), a saber, estabilidade emocional, extroversão, sociabilidade, escrupulosidade e abertura para a experiência. A questão é se o modelo não devesse ser acrescido de um sexto fator, a espiritualidade transcendente ${ }^{32}$ : “Ele é compreendido como a capacidade humana de se projetar para além da percepção espaço-temporal e de observar a vida a partir de um ponto de vista mais elevado e objetivo". 33

Observou-se em estudos recentes no contexto norte-americano, por exemplo, que a humildade e a singeleza fomentam a sensação de bem-estar em relação à saúde; que a capacidade de perdoar previne doenças cardíacas; que o mesmo vale para as relações conjugais, para uma convivência exitosa; que a capacidade de desenvolver a esperança é um dos principais traços da personalidade; que pessoas gratas se sentem melhor no dia-a-dia e conseguem lidar melhor com doenças crônicas. ${ }^{34}$ Naturalmente, cabe aqui a ressalva de que estes dados são fortemente influenciados pelo aspecto cultural e não podem ser transferidos diretamente para a realidade europeia ou latino-americana.

M. Utsch aponta as seguintes áreas de intersecção crítica entre Religião e Psicologia, a partir de sua tese de uma possibilidade de fecundação recíproca, que configuram três "modelos de religião psicológicos": a) o anelo pelo pai perfeito, a partir da Psicanálise clássica; b) autorrealização do estilo de vida próprio, a partir da Psicologia Humanista; c) unidade com o cosmos, a partir da Psicologia Transpessoal. ${ }^{35}$

A partir da teoria psicanalítica (a), a autocompreensão da religião não pode ser mais a mesma. Não há como retroceder ante a humilhação, ante os "severos golpes" que reabrem a "ferida narcísica", provocada pelo reconhecimento de Sigmund Freud de que o ser humano "não é senhor em sua própria casa", pois é governado pelo seu inconsciente. ${ }^{36}$ A hipótese do inconsciente é decisiva para a abordagem da religião, pois ela representa um elo entre aquilo que, entre outros elementos, subsumia-se ao conceito de alma, antes da virada positivista. ${ }^{37}$ Os ancestrais mais remotos na elaboração do conceito, por exemplo,

\footnotetext{
${ }^{32}$ Cf. M. UTSCH, Ist Glaube nur psychologisch erklärbar?, p. 18 s.

${ }^{33}$ Idem, p. 19.

${ }^{34}$ Idem, p. 19.

${ }^{35}$ Idem, p. 21.

${ }^{36}$ Cf. S. FREUD, Fixação em traumas: o inconsciente. In: FREUD, S. Obras Completas. Rio de Janeiro: Imago, 1976. p. 323-36. v. 16; S.FREUD, Uma dificuldade no caminho da psicanálise. In: FREUD, S. Obras Completas. p. 171-82. v. 17.

${ }^{37}$ Wilhelm Dilthey, em sua obra de referência Ideen über eine beschreibende und zergliedernde Psychologie de 1894, em meio ao advento da adoção do cânone positivista pela Psicologia $(e$, de modo geral, pelas Ciências do Espírito, digam-se, Humanas), já advertia: "Portanto, quando a psicologia explicativa subordina os fenômenos da vida psíquica a um número limitado de elementos explicativos univocamente determinados, de absoluto caráter hipotético, não podemos admitir que tal possa ser fundamentado pelos seus representantes como o destino inevitável de toda a psicologia, a partir da analogia do papel das hipóteses no conhecimento natural." W. Dilthey, Ideias acerca de uma Psicologia Descritiva e Analítica, 2008.
} 
C. G. Carus $^{38}$ e E. vonHartmann ${ }^{39}$, entendiam-no, justamente, sob o viés de uma crítica romântica ao racionalismo. $\bigcirc$ ganho prático na vivência da religião cristã ao assimilar o conceito seria o seguinte:

Graças aos conhecimentos psicanalíticos é possível examinar os reais motivos do agir humano [dentro de certos limites] e é revelada a força do inconsciente e dos desejos e anelos próprios. Vale a pena ir atrás dos rastros dos sentimentos intensos na própria história de vida, compreendê-los melhor e integrá-los. Um "teste de autenticidade" psicológico auxilia na vivência de um Cristianismo mais autêntico. $^{40}$

Todavia, ao direcionar o olhar da Teologia à Psicanálise ${ }^{41}$, é necessário fazer a ressalva em relação à parcialidade desta compreensão da alma humana:

Não obstante o auxílio dos conhecimentos da Psicanálise, não se pode ignorar a crítica fundamental do Cristianismo em relação a esta orientação de pesquisa. À luz da antropologia cristã, é um engano esperar que o ser humano como um todo possa ser analisado, compreendido e controlado. Os cristãos tentam através de retiros, de meditações frequentes ou da contemplação, entrar em contato com o mistério de Deus e alcançar paz, serenidade e confiança, sem, todavia, poder dispor deste Deus. ${ }^{42}$

Uma vez que a ilusão freudiana em relação a um futuro purificado de toda ilusão religiosa e exclusivamente embasado na racionalidade do princípio da realidade não se confirma, constata-se, au contraire, um verdadeiro boom de ofertas de auxílio à vida de caráter irracional, orientadas cosmovisivamente e, muitas vezes, críticas à ciência. ${ }^{43}$ Nesse contexto, a Psicologia Humanista (b), com sua centralização na concepção antropológica, segundo a qual, o ser humano possui um núcleo profundo, verdadeiro, autêntico e bom, o qual só precisa ser auxiliado em seu processo de autorrealização, corre o risco de transformar a própria Psicologia em uma religião.

${ }^{38}$ Cf., p. ex., C. G. CARUS, Vorlesung über Psychologie, 1829; E. R. von HARTMANN, Philosophie des Unbewussten, 1869.

${ }^{39}$ Cf. Eduard von HARTMANN, Philosophie des Unbewussten.Leipzig: Alfred Kröner, 1923.

${ }^{40}$ Cf. M. UTSCH, Ist Glaube nur psychologisch erklärbar?, p. 22.

${ }^{41} \mathrm{M}$. Utsch também se refere en passant à Psicologia Analítica de C. G. Jung. Reconhece que a perspectiva junguiana pode fomentar a fé, especialmente, pela importância dedicada aos símbolos, pelo destaque do conceito de "sincronicidade", através do qual a realidade oculta de Deus é explicitamente integrada; também pela importância dedicada aos sonhos, às emoções e à intuição. Não obstante, argumenta de forma crítica, que autênticas vivências religiosas, oriundas da relação com o transcendente, são substituídas por vivências psicológicas do próprio inconsciente religioso. Da mesma forma sumária, refere-se à Psicologia Individual de A. Adler, cujo conceito fundamental do "complexo de inferioridade" encontrou ampla receptividade no contexto teológico através de modelos evangelicais de aconselhamento pastoral. Todavia, questiona esta abordagem, ao indagar se o perdão seria capaz de ser gerado intrapsiquicamente? Cf. M. UTSCH, Ist Glaube nur psychologisch erklärbar?, p. 15.

${ }^{42}$ Idem, p. 22.

${ }^{43}$ M. UTSCH, Ist Glaube nur psychologisch erklärbar?, p. 16. 
Naturalmente, estão em jogo aqui, assim como em quaisquer modelos psicológicos, decisões prévias, conscientes ou inconscientes, acerca da compreensão do próprio ser humano, ou seja, pressupostos antropológicos e cosmovisivos. Se em Freud encontramos a forte carga (religiosa) do pessimismo antropológico semita, aliado ao pensamento evolutivo da luta pela sobrevivência e, na escola comportamental, uma tendência extrapolada no acento da inflexão do ser humano diante do meio, no humanismo, respectivamente, na escola psicológica que se sente herdeira desta concepção antropológica, ocorre uma espécie de incurvatio in se ipsum.

Desde que Deus se encontra em seu leito de morte, o indivíduo celebra sua epifania, seu Independence Day, seu século de independência e reflete este em um ego-monoteísmo: deseja ser si-mesmo, idêntico e uno consigo mesmo. No movimento para dentro de si, do louvor de si mesmo e do autoendeusamento, ele se perde..., a difusão da identidade divide-se em eus parciais; ele torna-se multipoliteísta, em uma mente multiforme. ${ }^{44}$

Os reflexos se espraiaram sobre toda a Psicologia e o diagnóstico de P. Vitz, neste tocante, não poderia ser mais devastador: "A Psicologia se transformou em uma forma de humanismo secular, que se fundamenta na rejeição de Deus e no endeusamento do simesmo" ${ }^{45}$ Assim, a questão não é ter ou não ter uma concepção antropológica de fundo, mas embasá-la explicitamente em um referencial, que, conforme $M$. Utsch, necessariamente encontra-se extrínseco à própria ciência psicológica:

Sem referência a uma axiologia explícita, a Psicologia pode assumir o status de uma religião, sem, todavia, conseguir correspondê-lo metodologicamente. Na raiz dos modelos psicológicos estão compreensões de ser humano, que, por sua vez, contêm e carregam valores implícitos. A "Psicologia como religião" superestima suas possibilidades, quando ela se deixa levar a interpretações de caráter moral da vida e "vende" asserções ético-normativas como psicologia. ${ }^{46}$

Já a Psicologia Transpessoal (c), segundo M. Utsch, propõe-se a ser uma nova dimensão da psicoterapia, que possui por objetivo conduzir o indivíduo para além de sua ancoração na consciência egoica para um estado de consciência transpessoal. Parte do pressuposto monista de que subjaz a tudo o que existe uma energia vital universal que lhe confere existência e sentido. Em outras palavras, que o núcleo pessoal do ser humano está imbricado com o cosmos e constitui com este uma unidade. As perturbações nessa

${ }^{44}$ Apud P. GROSS, Ich-Jagd. Im Unabhängigkeitsjahrhundert. Frankfurt a. M.: Suhrkamp, 1999, p. 25. In: M. UTSCH, Ist Glaube nur psychologisch erklärbar?, p 17. Cf. tb. S. V. NOÉ, Homo Narcissicus. Numen, v.5, n.1, p.41-59.

${ }^{45}$ Apud P. VITZ, Psychologie als Religion. Giessen, 1995, p. 11. In: M. UTSCH, Ist Glaube nur psychologisch erklärbar?, p 17.Cf. tb. G. J. de PAIVA, Espiritualidade na psicologia e psicologia na espiritualidade. Revista Magis. Cadernos de Fé e Cultura, no 47, 07/2005.

${ }^{46} \mathrm{M}$. UTSCH, Ist Glaube nur psychologisch erklärbar?, p. 17. 
relação, que se manifestam sob a forma de doenças, nesse sentido, são reflexos da negação daquilo que fundamentalmente define o ser humano: harmonia, vastidão e quietude. ${ }^{47}$

Assim, carrega em seu seio compreensões que a aproximam de filosofias de vida orientais e também de tradições ocidentais cristãs, denominadas genericamente de "mística". Todavia, diferentemente desta última, onde a experiência sui generis subjetiva e individual é determinante, acentua-se uma unidade genérica universalizante que, justamente, esvazia esta característica idiossincrática. Por outro lado, não há como ignorar que procura reestabelecer o contato do ser humano moderno com as forças vitais que o determinam, algo que outrora era domínio da religião, em uma época caracterizada pela assintocidade entre as diferentes dimensões da alma humana. Assim, in toto, M. Utsch resume as críticas em relação a esta variante psicoterápica da religião apontando para o perigo da "psicologização da religião e da sacralização da psicologia". ${ }^{48}$

\section{Conclusão e Perspectivas}

Naturalmente, a desconfiança que subjaz a relação entre Psicologia, Ciência da Religião e Teologia ao debruçaram-se sobre o estudo da religião não pode ser reduzida tão somente a uma "ignorância recíproca", mas tem a ver com uma disputa precípua pela primazia do conhecimento da alma humana. E este clima de concorrência não precisa necessariamente ser lastimado: ele pode, inclusive, ser imprescindível para a definição e demarcação epistemo-metodológica dessas áreas do saber, por um lado, e, por outro, pode ajudar a avistar espaços de intersecção entre estas.

Se o desenvolvimento da ciência moderna provocou uma diástase entre estas áreas, não há razões de cunho acadêmico para exacerbar as fronteiras que separam estas vias de conhecimento da alma humana. Todavia, no afã inter e multidisciplinar, deve-se assinalar também os riscos de uma precipitada fusão, seja ela originária da ingenuidade, da funcionalização ou do calculismo utilitarista de uma em relação à outra. $\bigcirc$ espaço de intersecção, portanto, precisa buscar ser uma zona de armistício, uma zona de exclusão de investidas beligerantes, cujo foco se concentra na possibilidade de um diálogo mútuo crítico. Eis o lugar da Ciência da Religião!

Neste espaço vale para todas estas áreas, ao se enfronharem do estudo da religião, aquilo que $\mathrm{H}$. Weder disse em relação à Teologia:

O assunto de que estamos tratando aqui está elementarmente relacionado àquilo que até hoje entendemos sob a palavra "Deus". Ocupar-se com este assunto é uma exigência incontornável à cientificidade da Teologia. Na casa da ciência,

\footnotetext{
${ }^{47}$ M. UTSCH, Ist Glaube nur psychologisch erklärbar?, p. 19.

${ }^{48}$ Idem, p. 20.
} 
todavia, o assunto não é Deus, mas o mundo, que precisa ser explorado e cujos enigmas precisam ser resolvidos. ${ }^{49}$

Portanto, ambas as renúncias são excruciantes: se, de um lado, renuncia-se ao códex acadêmico-científico paradigmático vigente, corre-se o risco de reativar modelos atávicos próximos à especulação e distantes da vida e do mundo; se, de outro, renuncia-se ao transcendente, seja qual for seu matiz, abdica-se epistemo e metodologicamente àquilo que, justamente, distingue o comportamento humano religioso das demais variações do seu comportamento; isto é, justamente a sua referência ao transcendente.

Eventualmente, trata-se apenas de uma variação da direção hermenêutica: se a partir da Teologia tem-se a alavanca na ação soberana do transcendente em relação ao imanente (do Jenseits em direção ao Diesseits) e a dimensão humana é compreendida como resposta a esta interpelação, nas ciências humanas, e aqui certo tipo de Psicologia, respectivamente, de Ciência da Religião, está incluída, o ponto de partida é justamente o ser humano que busca estabelecer relações com aquilo que the confere validade e sentido último: portanto, a partir do lado de cá, em relação ao lado de lá (do Diesseits em relação ao Jenseits).

Esse certo tipo de Psicologia cristalizou-se ao longo do século XX, desde seus ancestrais W. James e W. Wundt, como área do saber autônoma, denominada Psicologia da Religião. Tendo por mães "suficientemente boas" a Teologia e a Filosofia, não resistiu ao complexo de Édipo, identificando-se mais e mais, ao longo de sua história, com o pai dominante e promissor, o naturalismo. ${ }^{50}$ Com isso, também foi perdendo gradativamente sua referência ao transcendente, tonando-se uma órfã desamparada e com saudade da sua natureza perdida. Tenta, de diversas formas, preencher este vazio com premissas cosmovisivas, com aprioris antropológicos, com princípios normativos que, todavia, sem o devido alicerce na Teologia e na Filosofia, mostram-se como edifícios periclitantes.

Já uma interlocução crítica entre estas diferentes áreas do saber, tendo em comum o estudo da Religião e da Psicologia, pode estar mais bem alojado na casa da Ciência da Religião. Aqui, como demonstrado ao longo deste estudo, a área de intersecção abarca a compreensão de que há uma função psicológica da religião e uma função religiosa da psicologia. A questão não é separar as competências, mas compreender sua relevância para o estudo dos monstros ctônicos que povoam a alma humana, e, potencializando as competências distintas de ambas as áreas, promover a fecundidade mútua, em sentido negativo, como corretivo uma da outra, e, em sentido positivo, como aprofundamento do conhecimento da alma humana em sua relação com o transcendente.

\footnotetext{
${ }^{49}$ H. WEDER, Theologie als Wissenschaft, p. 3.

50 "A psicologia quer precisamente estudar o que não é nem a razão lógica nem o corpo. Disso ela quer fazer o estudo científico. A psicologia nasceu de um casal: a mãe tinha o espírito literário e religioso; o pai é a razão que trabalha com a ideia da explicação causal, como se faz na física e na química." Cf. A. VERGOTE, Necessidade e desejo na religião na ótica da psicologia, p.11.
} 


\section{Referências bibliográficas}

ÁVILA, Antonio. Para conhecer a Psicologia da Religião. São Paulo: Loyola, 2007.

DILTHEY, Wilhelm. Ideias acerca de uma Psicologia Descritiva e Analítica. Trad. Artur Morão. Covilhã: Lusofia-Press, 2008.

FRAAS, Hans-Jürgen. A Religiosidade Humana. Compêndio de Psicologia da Religião. São Leopoldo: Sinodal, 1997.

FREUD, S. Além do princípio do prazer. 1920. In: FREUD, S. Obras Completas. Rio de Janeiro: Imago, 1976. p.17-88. v.18.

Fixação em traumas: o inconsciente. 1917. Conferências Introdutórias sobre psicanálise. In: FREUD, S. Obras Completas. Rio de Janeiro: Imago, 1976. p.323-36. v.16.

HARTMANN, Eduard von. Philosophie des Unbewussten. 1. Teil: Phänomenologie des Unbewussten.; 2. Teil: Metaphysik des Unbewussten; 3. Teil: Das Unbewusste und der Darwinismus. 12. Auflage [1. Auflage: 1869]. Leipzig: Alfred Kröner, 1923. 1619 S.

JASPERS, Karl. Introdução ao Pensamento Filosófico. São Paulo: Cultrix, 1976.

PAIVA, Geraldo José. Ciência, Religião, Psicologia: Conhecimento e Comportamento. Psicologia: Reflexão e Crítica, 2002, 15(3), pp. 561-567.

PAIVA, Geraldo José. Espiritualidade na psicologia e psicologia na espiritualidade. Revista Magis. Cadernos de Fé e Cultura, n 47, 07/2005.

PAIVA, Geraldo José; ZANGARI, Wellington (Orgs.). A representação na religião: perspectivas psicológicas.São Paulo: Loyola, 2004.

PAIVA, Geraldo José de et al. Psicologia da Religião no Brasil: a produção em periódicos e livros. Psicologia: Teoria e Pesquisa, Brasília, v. 25, n. 3, Setembro de 2009. Disponível em: <http:/ / www.scielo.br/ scielo.php?script=sci_arttext\&pid=SO102-

377220090003000198 Ing=en\&unrm=iso > Acesso em: 27 jun. 2013.

UTSCH, Michael. Tarefas e limites da Psicologia da Religião: Uma perspectiva dialógica. Numen. v.16, n. 2, 2013. p. 539-555.

UTSCH, Michael. Ist Glaube nur psychologisch erklärbar? Psychologie im Wandel: Von der Religionskritik zur Glaubensvertiefung. Berlim: IGUW, 2012. Disponível em: <http:/ / www.iguw.de/ textsammlung/ view/article/ ist-glaube-nur-psychologischerklaerbar.html> Acesso em: 26 abr. 2013.

UTSCH, Michael. Religionspsychologie. Voraussetzungen, Grundlagen, Forschungsüberblick. Berlin: Kohlhammer, 1998.

UTSCH, Michael. Religião e Psicologia. Estudos Teológicos, v. 53, n. 2, 2013. p. 364-381. 
VERGOTE, A. Necessidade e desejo na religião na ótica da psicologia. In: PAIVA, Geraldo José de. Entre necessidade e desejo - Diálogos da psicologia com a religião. São Paulo: Loyola, 2001.

WEDER, Hans. Theologie als Wissenschaft. Theologische Literaturzeitung, v. 137, n. 12, col. 1295-1308, dez. 2012. 